\title{
A Note on Three New Sources
}

Three important books were published after the completion of the present work. Several of the German documents, particularly those bearing on the politics of Heisenberg and other German physicists during the Nazi period, are now available in English translation in K. Hentschel and A. Hentschel, Physics and National Socialism: An Anthology of Primary Sources (Basel, Boston, and Berlin, 1996). Further material on the compromises of Otto Hahn and others is to be found in R. L. Sime, Lise Meitner: A Life in Physics (Berkeley, 1996). And a running critical commentary on the Farm Hall transcripts has been provided by J. Bernstein, Hitler's Uranium Club (Woodbury, N.Y., 1996). Attention should also be drawn to the reissue of $\mathrm{S}$. Goudsmit's $A L S O S$, with a new introduction by D. C. Cassidy (Woodbury, N.Y., 1996). Though unable to have made full use of these new sources, I have added a few references to them in the footnotes, which may prove useful to readers wishing to have access to certain documents in translation. 
